\title{
VIVÊNCIA NA AGRICULTURA FAMILIAR: MÉTODO DE APRENDIZAGEM PARA O CURSO DE AGRONOMIA
}

\section{EXPERIENCE IN FAMILY AGRICULTURE: METHOD OF LEARNING FOR THE COURSE OF AGRONOMY}

\author{
Jhemyson Jhonathan da Silveira Reis ${ }^{1}$; Cleison Freitas da Silva ${ }^{2}$; Bárbara Maísa Nunes \\ Araújo $^{3}$; Pablo Radamés Cabral de França ${ }^{4}$
}

DOI: $\underline{\text { https://doi.org/10.31692/978-65-991061-7-0.482-485 }}$

\section{INTRODUÇÃO}

O Instituto Federal de Educação, Ciência e Tecnologia do Pará (IFPA) - Campus Castanhal tem buscado construir um desenho curricular para os cursos de graduação que atenda as demandas das situações existenciais concretas das populações do campo. Para isso, vem sendo proposto o exercício de confrontar a teoria e a realidade, de modo a inserir os educandos no âmbito da realidade regional, conduzindo-os a uma participação ativa e efetiva na produção do conhecimento, além de possibilitar sua iniciação na prática metodológica da pesquisa e da extensão (IFPA, 2010).

Com isso o estágio I proporciona observação e análise do sistema famíliaestabelecimento na sua complexidade e o estudo dos diferentes tipos de atividades existentes na agropecuária (MELO et al., 2018). Dessa forma, objetivou-se na vivencia compreender o cotidiano e as atividades realizadas pelos agricultores contextualizando o meio, o sistema de produção e as técnicas utilizadas pelos agricultores familiares. .

As realidades amazônicas têm sido cada vez mais exigentes a necessidade de construir novas metodologias, abordagens, conteúdos e práticas no percurso formativo dos profissionais de Agronomia que, partindo da condição concreta das diferentes realidades, se preocupem em compreender as diferentes lógicas sócio produtivas e culturais de uma determinada região (BATISTA, 2012). Resultando na ganho de experiência de campo fortalecendo a formação do profissional da agronomia.

\section{RELATO DE EXPERIÊNCIA}

O estágio de vivencia I ocorreu no período de 26 de janeiro a 06 de fevereiro de 2018. Participaram deste espaço de formação 26 discentes do curso de Bacharelado em Agronomia do IFPA/Campus Castanhal, sob a supervisão de docentes do Instituto.

\footnotetext{
${ }^{1}$ Bacharelado em Agrônoma, IFPA, reis.jhemyson@gmail.com

${ }^{2}$ Bacharelado em Agrônoma, IFPA, cleisonfreitasbr@gmail.com

${ }^{3}$ Bacharelado em Agrônoma, IFPA, barbaramaisa12@ hotmail.com

${ }^{4}$ Doutor em Agronomia, IFPA, pablo.radames@ hotmail.com
} 
O estágio foi realizado em Cametá, município do estado do Pará, no Brasil. Localiza-se a uma latitude $02^{\circ} 14^{\prime} 40^{\prime \prime}$ Sul e a longitude $49^{\circ} 29^{\prime} 45^{\prime \prime}$ Oeste, estando a uma altitude de 10 metros acima do nível do mar. Sua população estimada em 2017 era de 134.100 habitantes com extensão territorial de 3.081,367 quilômetros quadrados.

Propriedade de Dona Margarete e Seu Nei composta em um total de nove (9) membros na unidade familiar, localizada na Comunidade Mathias no Ramal São Francisco que fica aproximadamente $18 \mathrm{Km}$ da cidade de Cametá, com área total de $200 \mathrm{~m}$ de frente por $500 \mathrm{~m}$ de fundo, ou, $1 / 2$ lote. Filhos de cametaenses, moradores da zona rural, residem na atual propriedade há 8 anos. O antigo proprietário possuía plantio de açaí (imagem 1), que permanece até a presente dada do estágio, e criação de animais destinados a venda.

Imagem 1: Área plantada de açaí (do antigo proprietário). Fonte: acervo pessoal

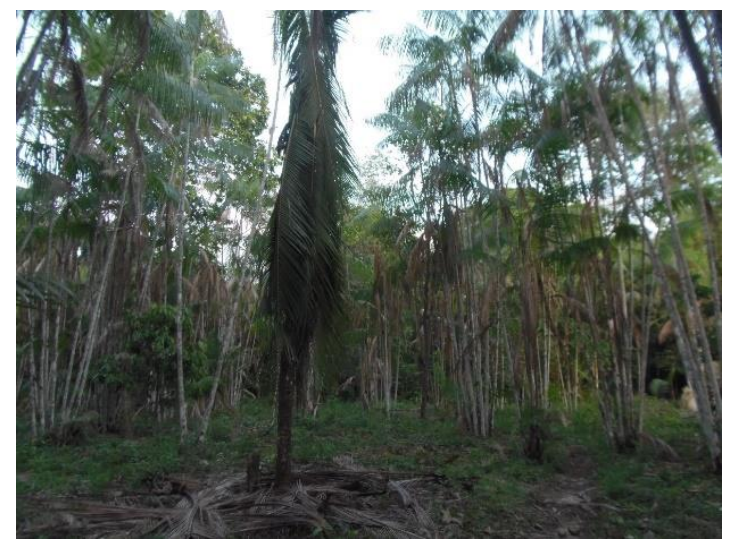

A propriedade tem como atividade principal o roçado com o sistema de "roça e queima” (imagem 2), sem o uso de defensivos agrícolas ou adubação química, para o cultivo de mandioca (Manihot esculenta Crantz), milho (Zea mays), arroz (Oryza spp.), melancia (Citrullus lanatus), maxixe (Cucumis anguria). Além do plantio feito na propriedade possuem roça em uma propriedade (cedida pelo pai do "Seu Nei”) de uso familiar. Também é realizado o extrativismo de subsistência onde se retira Bacuri (Platonia insignis Mart.), castanha-dopará (Bertholletia excelsa), cupuaçu (Theobroma grandiflorum) e açaí (Euterpe oleracea) da área de plantio adquirida na compra da propriedade.

Durante uma roda de conversa, a família e vizinhos conversavam sobre as dificuldades no campo quando um dos agricultores falava da educação e se pronunciou a respeito:

\footnotetext{
"O acesso as escolas e a quantidade de centros educativos presentes nas comunidades são outro ponto que deixam a desejar e acabam sendo um dos fatores que causam a falta de estímulos ao jovem em permanecerem nas escolas já que muitos professores deixam de ir pela falta de alunos" (Seu Marcelo, 2018).
} 
Imagem 2: sistema de roça e queima. Fonte: acervo pessoal

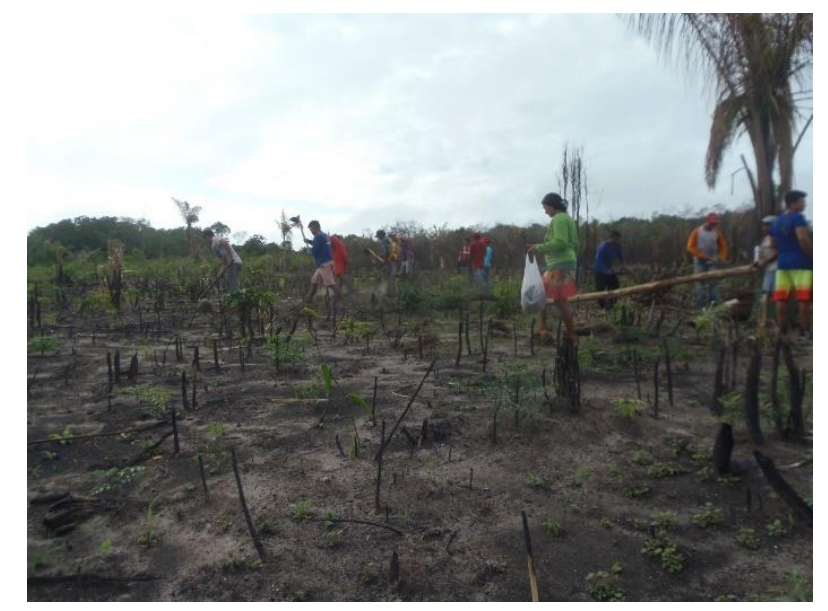

Na propriedade não se faz criação de animais numa grande escala sendo a principal criação a de galinha caipira criadas soltas tendo um número aproximado de 300 animais dentre esses indivíduos filhotes, jovens e adultos, tendo também um curral com 3 porcos.

\section{CONSIDERAÇÕES}

A propriedade apresenta uma grande diversidade produtiva, desde o cultivo a criação, que contabilizavam com a renda familiar. No entanto, sua produção se limitava, basicamente ao consumo e a venda semanal dos gêneros produzidos como: farinha de mandioca, farinha de tapioca (com castanha e sem castanhal), beiju, tucupi, goma de tapioca e a venda de aves caipiras adultas. Tais produtos apresentam potencial no sentido de aumento de sua produção, que acaba sendo limitado pela idade e o quantitativo de pessoas disponíveis para auxiliar nos processos produtivos.

A comunidade apresenta poucas vias de escoamento de suas produções, sendo que as mesmas se encontram em estado precário. Além das estradas serem um fator limitante do escoamento, em períodos mais chuvosos alguns trechos se encontram submersos prejudicando ainda mais o transporte.

Nesse contexto, a vivencia proporciona a experiência e o convívio com a família com o modo de produção, de tal modo que os saberes popular, técnico e cultural se juntam para forma um conhecimento único, mais ao mesmo tempo coeso.

O estágio proporcionado pelo IFPA-Castanhal possibilita associar a prática com a teoria dada em sala de aula, sendo essencial para o processo de aprendizagem de um profissional diferenciado. O estágio possibilita o aluno participar de experiências reais da realidade do agricultor familiar, sendo um momento de aprendizado único e fundamental. 


\section{REFERÊNCIAS}

BATISTA, M. G. Qual a abordagem para a agronomia? Comunicação Oral. Aula ministrada na disciplina de Sistema de Cultivo. IFPA - Campus Castanhal, 2012. (MIMEO)

MELO, A. T. M.; BATISTA, M. G.; COELHO, R. F. R. Guia Metodológico: estagio supervisionado de vivência do curso de agronomia do IFPA Campus castanhal. Jan. 2018. $16 p$

IFPA, Instituto Federal de Educação, Ciência e Tecnologia do Pará, PPC - AGRONOMIA, Projeto Político Pedagógico do Curso de Agronomia do IFPA/Campus Castanhal. Castanhal: IFPA, 2010. 109p. 